\title{
Video Case :Extraction of a Coin from the Stomach of a 6 Months
} Infant

\section{Zaher T.}

Endemic and Tropical Medicine Department, Faculty of Medicine, Zagazig University, Egypt. tareqzaher@zu.edu.eg

\section{Comment}

An Egyptian coin was accidentally ingested by a $1 \mathrm{mg}$ midazolam was administered 6 months female infant . Repeated X rays over 2 intramuscularly . Endoscopy revealed impacted weeks revealed the coin in the upper abdomen. Upper gastrointestinal endoscopy using Olympus GIF Q160 endoscope was performed. coin in the antrum of the stomach. Repeated attempts using shark tooth forceps were done. Finally the coin was successfully extracted. 